\title{
Diagnostics of Sensory Ataxia in Patients with Sensory Predominant Chronic Inflammatory Demyelinating Polyneuropathy from Republic of Sakha (Yakutia) and Krasnoyarsk Region
}

\author{
T. E. Popova', N. A. Shnayder¹, M. M. Petrova', A. A. Tappakhov², T. Ya. Nikolaeva², \\ E. E. Konnikova ${ }^{2}$ \\ ${ }^{1}$ Krasnoyarsk State Medical University Named after Professor V.F. Voino-Yasenetsky, Krasnoyarsk, Russia \\ ${ }^{2}$ M.K. Ammosov North-Eastern Federal University, Yakutsk, Russia \\ Email: tata2504@yandex.ru,naschnaider@yandex.ru,stk99@yandex.ru, aa.tappakhov@s-vfu.ru, \\ tyanic@mail.ru, edilia@mail.ru
}

Received 1 June 2016; accepted 5 July 2016; published 8 July 2016

Copyright (C) 2016 by authors and Scientific Research Publishing Inc.

This work is licensed under the Creative Commons Attribution International License (CC BY).

http://creativecommons.org/licenses/by/4.0/

(c) (i)

Open Access

\begin{abstract}
Materials and Methods: A group of healthy volunteers (24 people) and patients with SP-CIDP from Republic of Sakha (Yakutia) (42 people) and Krasnoyarsk region (87 people). Diagnostics Methods: Clinical neurologic, neurophysiological. Results: The results of stabilometry research of patients with SP-CIDP have revealed area expansion of pressure centre in phase EO and EC with deflection PC forward by anteropulsion type among patients with SP-CIDP from Republic of Sakha (Yakutia). Also in the Yakut group has been noted to have severer clinical course in comparison with inhabitants of Krasnoyarsk region. Conclusion: The method of computer stabilometry allows estimating objectively presence and degree of manifestation of sensitive ataxia in patients with SP-CIDP.
\end{abstract}

\section{Keywords}

Sensory Predominant Chronic Inflammatory Demyelinating Polyneuropathy (SP-CIDP), Diagnostics, Sensory Ataxia, Stabilometry

\section{Introduction}

Motor disturbances and coordination disorders take a predominant place among the causes of restriction of pa-

How to cite this paper: Popova, T.E., et al. (2016) Diagnostics of Sensory Ataxia in Patients with Sensory Predominant Chronic Inflammatory Demyelinating Polyneuropathy from Republic of Sakha (Yakutia) and Krasnoyarsk Region. Journal of Biosciences and Medicines, 4, 36-44. http://dx.doi.org/10.4236/jbm.2016.47005 
tients' vital activity chronic peripheral polyneuropathies, including sensory predominant chronic inflammatory demyelinating polyneuropathy (SP-CIDP). A leading symptom of motor SP-CIDP disorders is sensory ataxia, which is displayed by instability strengthening at eyes close position [1]-[4]. Instability severity thus depends not only on degree of peripheral neuropathy, but also on the type of afferent fibers. For example, polyneuropathy with affection of thick mylienating afferent fibers (as Charcot-Marie-Tooth disease 1A type) minor alterations in the vertical position, even with eyes close [5] [6]. Polyneuropathy with the affection of medium-size afferent fibers (diabetic polyneuropathy (DPN), SP-CIDP) characterized by instability in eyes close position [4][6]. Possible cause of instability in patients with DPN and SP-CIDP is the lesion of types I and Ia afferent fibers. II type fibers innervate secondary terminals, which sensitive to changes of muscle length, also represent more important source of sensitive uptake for control of the position, than Ia fibers [5]-[9].

Due to various sensitive systems (vestibular, proprioceptive and visual) brain receives the information about the process deviation from the vertical. If physically beam balance in equilibrio is static, physiological rest means absence of feedback for correction of body deflection [10]. Stabilometry is the most exact method, allowing to make an assessment of body balance, to investigate quality of balance function, to study the contribution of various systems to maintenance of vertical position: vestibular mechanisms of deduction of balance and motor activity, function of proprioceptive system, visual evaluator and other systems of organism expressly or by implication influencing on postural reaction [4] [11]-[15].

The particular interest represents the comparison of expressiveness of sensory ataxia in ethnic and climategeographic aspect. So, Republic of Sakha (Yakutia) is the subject of the Russian Federation first by the area having a total area of continental and island 3.1 million $\mathrm{km}^{2}$. The climate is sharply continental, differs by long winter and short summer. The maximum average temperatures of the coldest month-January and the warmest-July compound $70^{\circ} \mathrm{C}-75^{\circ} \mathrm{C}$. Krasnoyarsk region—the subject of the Russian Federation second by the area, occupies 2.36 million $\mathrm{km}^{2}$. In connection with the big extent of region the edge climate is very impure. The average temperature of January compounds from $-36^{\circ} \mathrm{C}$ in the north to $-18^{\circ} \mathrm{C}$ in the south, the average temperature of July compounds from $+13^{\circ} \mathrm{C}$ in the north to $+20^{\circ} \mathrm{C}-+25^{\circ} \mathrm{C}$ in the south.

Research aim: To estimate expressiveness of sensory ataxia in patients with sensory predominant chronic inflammatory demyelinating polyneuropathy in two regions of the Russian Federation: Republic of Sakha (Yakutia) and Krasnoyarsk region.

\section{Materials and Methods}

Our clinical-laboratory researches have been made on the basis of department of medical genetics and clinical neurophysiology of Institute postgraduate education and on the basis of Krasnoyarsk state medical University clinic named after Prof. V.F. Voino-Yasenetsky and Clinic of Medical institute of North-Eastern federal university named after M.K. Ammosov since September 2013 till December 2015 within the complex researches on the topic "Epidemiological, genetic and neurophysiological aspects of diseases of nervous system (central, peripheral and vegetative) and preventive medicine” (registration 0120.0807480). Local ethical committee (report № 51/2013 from 28.10.2014) approved research.

We've examined 3 groups: group 1-healthy control, group 2-patients with SP-CIDP from Republic of Sakha (Yakutia), group 3-patients with SP-CIDP from Krasnoyarsk region. All patients passed careful pre-award anamnestic and clinical selection which was carried out by stratified randomization method with the use of criteria of inclusion and exception, developed according to the purpose and problems of the present research. Criteria for inclusion: verified SP-CIDP diagnosis, male and female gender, age of patients from 18 years and older, constant residence registration on the territory of the Republic of Sakha (Yakutia) and Krasnoyarsk region, the patient's consent to research, absence of severe somatic diseases that impede research. Criteria of exception: peripheral neuropathy of other genesis, age of patients up to 18 years old, no patient's consent to research; there are severe somatic disorders that impede research.

Social-hygienic and clinical-diagnostic registration signs for observation units have been received from CIDP patients' register created in Republic of Sakha (Yakutia) and Krasnoyarsk region and also by copy data from statistical forms. The clinical data were received in the course of direct examination of the patients.

Somatic research included measurement of arterial pressure, pulse, lungs auscultation, palpation and percussion of abdomen, weight and height measurement, waist measurement, diameter of upper and lower extremities (with measure tape). Analysis of herpetic infection in anamnesis was found out. Standard neurologic examina- 
tion included the exam of cranial nerves, motor function (muscle tone, muscle strength, including posture and walking on forefoot and heels, tendon reflex), sensitive functions (analyses of pain sensitivity by means of the neurologic platen, tactile sensitivity with monofilament Thio-Feel $10 \mathrm{~g}$ (Viatris, Germany), muscular sense, temperature on distal parts of extremities — with electronic dermal thermometer AND (Japan)), coordination.

Stabilometry for the assessment of presence and degree of postural instability was conducted by diagnostic platform "MBN Stabilo" (MBN, Moscow) [1] [4] [12]. Selection criteria for research were: ability of the patient independently (without a support) to conserve balance standing not less than 2 minutes; absence of serious motor and cognitive disorders and also pathology of skeletal-articular system interfering carrying out research, and non-corrected sight disorders. Stabilometry was carried out in the occluded room with the sufficient area $\left(20 \mathrm{~m}^{2}\right)$ for prevention of acoustic orientation of the patient in space with the doctor; stabilometric platform was positioned on distance more than 1 meter from walls; any noise hindrances were excluded, capable to distract attention of the patient, general level of noise in the room did not exceed $40 \mathrm{~dB}$ (by ISO); illumination intensity in the room was 40 lux. The patient stand on the platform in socks by the European variant of feet position (heels together, forefeet are dissolved to 30 degrees angle). The choice of feet position was caused by its nature and maximum convenience for the patient and also that axes of subtalar joints appear to be parallel and direct strictly in the sagittal plane [12].

Before stabilometric research we measured the following individual parameters of the examined, necessary for calculation of stabilometic characteristics:

- Length of foot (mm) - distance from the back surface of calcaneal tuber to the nail phalanx of the most prominent forward toe;

- Distance of anklebone-forefoot (mm) — distance from projection to support plane of apex of outside anklebone to nail phalanx of the most prominent forward toe;

- Clinical base (mm) — distance between the front-upper spines of iliac bones;

- Height (sm).

After putting feet on the platform, the patient took vertical position. Romberg's test was used due to the European variant which had 2 phases: with eyes open (EO) and eyes close (EC). We were waiting 10 seconds from the moment of patient's readiness to the beginning of registration. In the course of registration with EO, the patient focused his eyes on a special mark (a red circle with $5 \mathrm{~cm}$ diameter) on a distance of 2 meters directly before the patient's eyes; in phase EC, the patient closed eyes and continued to hold the set position by the computer command. The aim of phase EC was excluding of visual analyzer influence and vertical position preserved only for proprioception. Each phase of the research was made during 51.2 seconds. Research was interrupted and started again in case of distracting factors, capable to deform results: tussiculations, scratching, turns of the head, talking, external sound and other stimulants.

The following key parameters of stabilometry were exposed to the analysis:

- Average position of centre of pressure (CP) — characterizes position of CP in the frame of axes (X, Y) bases of support, reflecting global characteristics of body balance (shift in sagittal and frontal axis);

- Sway area (S) - the plane part circumscribed to the curve of statokineziogram. In math equivalent represents ellipse covering $90 \%$ of all measurements during research;

- $\quad$ Sway velocity (V) — characterizes the size of path, CP passed per time unit;

- Romberg quotient (QR) —attitude to sway in phase EO to the sway area in phase EC, expressed in percentage; it is applied to quantitative definition of ratio between visual and proprioreceptive systems of balance control in the basic position.

Statistical data processing was made with use of applied programs IBM SPSS Statistics 19 and Statistica 10 (StatSoft, USA). Modern international requirements to representation of results of statistical analysis in articles and dissertations were considered for carrying out of statistical data processing and interpretation of the received results. For determine the type of data distribution the Kolmogorov-Smirnov test has been used. Because the data is not subject to the law of normality distribution, descriptive statistics quantitative data is given as medians and $25^{\text {th }}$ and $75^{\text {th }}$ quartiles (Mediane [25th quartile; 75th quartile]), and for comparative statistics nonparametric methods has been used. For comparison of three independent groups quantitative data applied Kruskal-Wallis test with the critical level of significance $p \leq 0.05$. Upon detection of statistically significant differences between the three groups held a further paired comparison of groups using the Mann-Whitney test with a new critical significance level $\mathrm{p} \leq 0.017(0.05 / 3=0.017)[16]$. 


\section{Results and Discussions}

\section{Clinical Characteristic of the Examined}

Group 1 included 24 healthy volunteers with average age 33 years old [23.5; 47]: 10 (41.7\%) women and 14 (58.3\%) men.

Group 2 included 42 patients with SP-CIDP, living on territory of Republic of Sakha (Yakutia): 39 (92.9\%)— females and 3 (7.1\%)—-males from 18 till 62 years old. A median of age of debut SP-CIDP_43 years old [30; 48]. Ethnic were: 27/42 people from the Yakut ethnic group (64.3\% $\pm 7.4 \%$ ), 14/42 people-Russian (33.3\% \pm 7.3\%) and 1/42 people-Kirghiz (2.4\%). The majority examined people (38 people; 90.5\%) lived in Yakutsk, others (4 people; $9.5 \%$ ) - in areas of Republic of Sakha (Yakutia).

Group 3 were 87 people living on territory of Krasnoyarsk region: females—54 (62.1\%), males—33 (37.9\%) people with average age-28 years old [22; 35]. A median of age of debut-27 years old [20; 35]. 77 people (88.5\%)-Russian, 10 people (11.5\%)—representatives of other ethnic groups. The majority examined (49 people; 56.3\%) lived in Krasnoyarsk, others (38 people; 43.7\%)_in areas of Krasnoyarsk region.

SP-CIDP debuted statistically significantly earlier in patients from Krasnoyarsk region: a median of age of debut of disease was 27 years old [20; 35] against 43 years old [30; 48] in patients from Republic of Sakha (Yakutia) ( $<$ 0.001). SP-CIDP has been diagnosed for the first time among 42 patients $(100 \%)$ from Republic of Sakha (Yakutia) (and in 62 patients (72.9\%) from Krasnoyarsk region ( $p=0.027)$. Patients with SP-CIDP from Republic of Sakha (Yakutia) and Krasnoyarsk region have frequency of clinical manifestations of chronic herpes-viral infection in anamnesis: in $71.4 \%$ against $74.7 \%$ of patients $(p=0.797)$. Among the examined contingent, 83.3\% of patients from Republic of Sakha (Yakutia) and 69\% of patients from Krasnoyarsk region had cases of chronic herpes-viral infection among members of one family ( $p=0.095)$.

By ELISA (enzyme linked immunosorbent assay) results, active mixt-herpes-viral infection was marked equally often both in patients from Republic of Sakha (Yakutia) (81.0\%) and among inhabitants of Krasnoyarsk region (83.9\%) ( $p>0.05$ ). Activity of cytomegalovirus infection and herpes simplex virus 1,2 groups was comparable in both groups ( $p>0.05$ ); active Epstein-Barr virus (EBV) infection was revealed in $4.8 \%$ cases from Republic of Sakha (Yakutia) (and in 79.3\% cases from Krasnoyarsk region ( $<<0.001$ ) that is consistent with the importance of chronic EBV infection in SP-CIDP genesis according to foreign authors (Lünemann J. D. et al., 2010). It is possible to assume that herpes infection is itself the starting mechanism of autoimmune process with development of demylienating process in polyneuropathy.

Patients with SP-CIDP had signs of sensitive polyneuropathy when polymodal sensitivity method was applied: $100 \%$ of patients with SP-CIDP from Krasnoyarsk region and 97.6\% of patients from Republic of Sakha (Yakutia). Frequently sensitive infringements were combined with angiotrophoneurosis: 71.4\% of patients from Republic of Sakha (Yakutia) and 94.3\% of patients from Krasnoyarsk region ( $p<0.001$ ). Painful hyperesthesia prevailed among sensitivity disorders: $71.4 \%$ of patients from Republic of Sakha (Yakutia) against 90.8\%from Krasnoyarsk region $(\mathrm{p}=0.004)$. Hypoesthesia at level of distal departments of lower extremities were revealed only in patients from Republic of Sakha (Yakutia): 21.4\%. Paresthesia at level of distal departments of upper and lower extremities prevailed in patients from Republic of Sakha (Yakutia): 35.7\% of patients of the Yakut group and $17.2 \%$ of patients of Krasnoyarsk group $(\mathrm{p}=0.036)$. Cramp and decrease in tactile sensitivity on pendent surface of feet were equally often met in both groups of patients $(p>0.05)$.

Patients of the Yakut group had hyporeflexia from level of upper extremities more often from reflex sphere: $38.1 \%$ of patients from Republic of Sakha (Yakutia) and 16.1\% of patients from Krasnoyarsk region ( $p=0.012$ ). The hyporeflexia from level of lower extremities also was more often marked in patients from Republic of Sakha (Yakutia): 59.5\% and 35.6\% accordingly $(\mathrm{p}=0.027)$.

As a whole, severer SP-CIDP clinical course was noted in patients from Republic of Sakha (Yakutia) in comparison with patients from Krasnoyarsk region, thus in the Yakut group fallout symptoms (hypoesthesia, hyporeflexia) was more often met.

Table 1 shows main results of stabilometry in three groups.

In control group a median of sway area in phase EO-70.15 and in phase EC-75.14 $\mathrm{mm}^{2}$, a median of sway velocity in phase EO- $8.7 \mathrm{~mm} / \mathrm{s}$ and in phase EC-10.9 mm/s (Table 1). Deflection of CP in a sagittal plane back was registered (Figure 1).

Patients from Republic of Sakha (Yakutia) had a median of sway area in phase EO 167.8 and in phase EC$198.4 \mathrm{~mm}^{2}$, a median of sway velocity in phase EO-6.9 mm/s and in phase EC-9.7 mm/s (Table 1). Deflection 


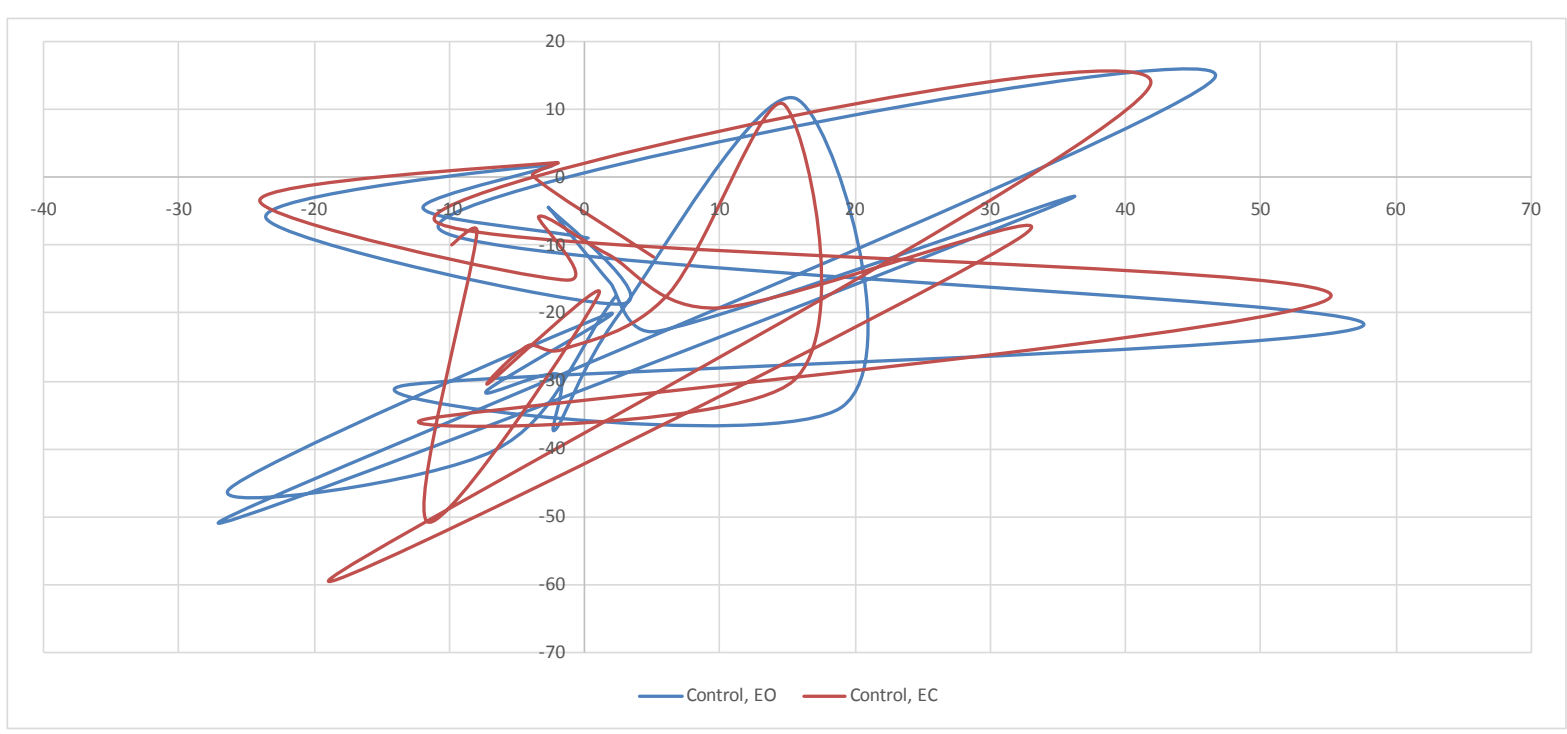

Figure 1. Statokineziogram in control group: dark blue line-in phase EO, red line-in phase EC.

Table 1. Results of stabilometry in patients with sensory predominant sensitive chronic inflammatory demyelinating polyneuropathy from Republic of Sakha (Yakutia) and Krasnoyarsk region in comparison with control.

\begin{tabular}{|c|c|c|c|c|}
\hline \multirow{2}{*}{$\begin{array}{l}\text { The analyzed } \\
\text { parameters }\end{array}$} & Control group, $\mathrm{N}=24$ & $\begin{array}{l}\text { Patients from Republic of } \\
\text { Sakha (Yakutia), N = } 42\end{array}$ & $\begin{array}{l}\text { Patients from Krasnoyarsk } \\
\text { region, } \mathrm{N}=84\end{array}$ & \multirow{2}{*}{$\begin{array}{c}\text { p-level, } \\
\text { Kruskal-Wallis test }\end{array}$} \\
\hline & Median, $\left[\mathrm{P}_{25} ; \mathrm{P}_{75}\right]$ & Median, $\left[\mathrm{P}_{25} ; \mathrm{P}_{75}\right]$ & Median, $\left[\mathrm{P}_{25} ; \mathrm{P}_{75}\right]$ & \\
\hline $\mathrm{S}, \mathrm{EO}\left(\mathrm{mm}^{2}\right)$ & 70.15 [42.2; 114.6] & $167.8[109.7 ; 330.5]$ & $83.17[54.95 ; 125.42]$ & $<0.001^{1,3}$ \\
\hline $\mathrm{S}, \mathrm{EC}\left(\mathrm{mm}^{2}\right)$ & $75.14[37.9 ; 115]$ & 198.4 [117; 352.7] & $105.03[66.3 ; 159.3]$ & $<0.001^{1,2,3}$ \\
\hline $\mathrm{V}, \mathrm{EO}(\mathrm{mm} / \mathrm{s})$ & $8.7[6.6 ; 10.6]$ & $6.9[5.5 ; 9.3]$ & $8.74[7.52 ; 9.86]$ & $<0.001^{1,3}$ \\
\hline $\mathrm{V}, \mathrm{EC}(\mathrm{mm} / \mathrm{s})$ & $10.9[9.15 ; 14.4]$ & $9.7[7 ; 13.3]$ & $11.97[10.14 ; 14.7]$ & $0.017^{3}$ \\
\hline $\mathrm{Y}, \mathrm{EO}(\mathrm{mm})$ & $-19.43[-31.0 ;-5.2]$ & $19.8[12.3 ; 30.3]$ & $-16.12[-25.38 ;-3.33]$ & $<0.001^{1,3}$ \\
\hline $\mathrm{Y}, \mathrm{EC}(\mathrm{mm})$ & $-13.3[-24.9 ;-5.9]$ & $19.8[1.6 ; 27.9]$ & $-12.99[-25.27 ;-4.94]$ & $<0.001^{1,3}$ \\
\hline $\mathrm{X}, \mathrm{EO}(\mathrm{mm})$ & $-0.79[-8.9 ; 4.0]$ & $2[-1.4 ; 6.5]$ & $0.63[-4.68 ; 3.13]$ & 0.199 \\
\hline $\mathrm{X}, \mathrm{EC}(\mathrm{mm})$ & $-1.87[-8.88 ; 8.08]$ & $4.7[-0.6 ; 7.9]$ & $-0.715[-5.03 ; 4.16]$ & 0.054 \\
\hline $\mathrm{QR}, \%$ & 112.18 [65.22; 159] & $103[71 ; 164]$ & 137.25 [82.43; 193.85] & 0.286 \\
\hline
\end{tabular}

Notes: X-position of CP in frontal plane; Y—average position of CP in sagittal plane; S—sway area; V—sway velocity; QR—Romberg quotient; $\mathrm{EO}$ - data is resulted for a phase with eyes open; EC—-data is resulted for a phase with eyes close; ${ }^{1}$ there are statistical differences between patients with SP-CIDP from Republic Sakha (Yakutia) and control group; ${ }^{2}$ there are statistical differences between patients with SP-CIDP from Kransoyarsk region and control group; ${ }^{3}$ there are statistical differences between patients with SP-CIDP from Republic Sakha (Yakutia) and Krasnoyarsk region.

of CP in sagittal plane forward (Figure 2) was registered.

Patients with SP-CIDP from Krasnoyarsk region had median of sway area in phase EO 83.17 and in phase EC-105.03 mm², a median of sway velocity in phase EO-8.74 mm/s and in phase EC_-11.97 mm/s (Table 1). Deflection of CP in sagittal plane back (Figure 3) was registered.

Figures 4-6 show comparative statokineziogramms of studied groups. Analysis using the Kruskal-Wallis test showed that statistically significant differences in the three groups are all the investigated parameters, except for the position of CP in the frontal plane in both study phases and the Romberg quotient (Table 1). Further statistical analysis was performed using the Mann-Whitney test with a new critical significance level (p < 0.017). Thus, statistically significant differences between patients from Repiblic Sakha (Yakutia) and control group were revealed in both phases of the study on position CP in the sagittal plane and sway area, and sway velocity in the phase EO. Comparison of patients from Krasnoyarsk region with control group showed statistically significant differences only in sway area in phase EC. Statistically significant differences between patients from 


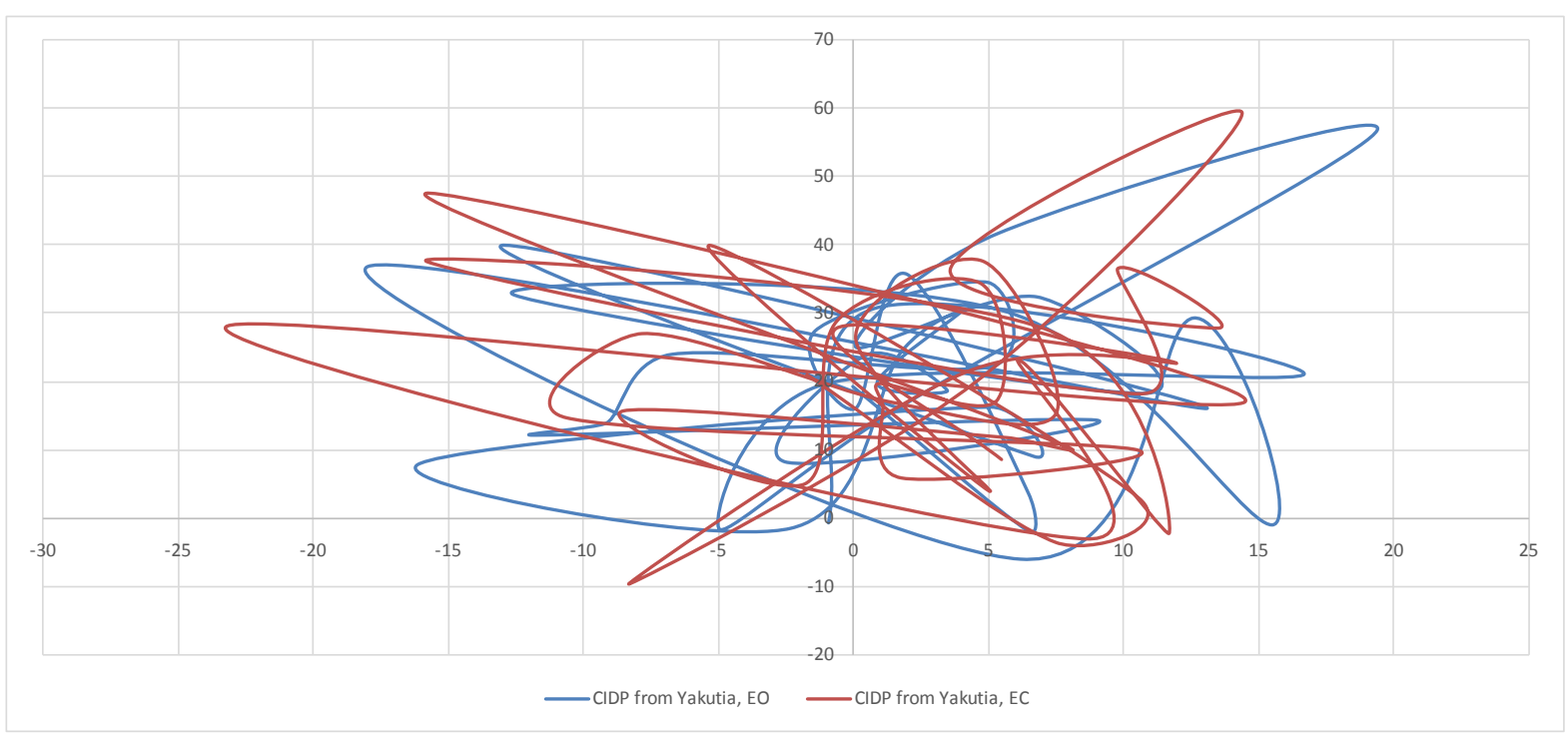

Figure 2. Statokineziogram in patients with SP-CIDP from Republic of Sakha (Yakutia): dark blue line—in phase EO, red line-in phase EC.

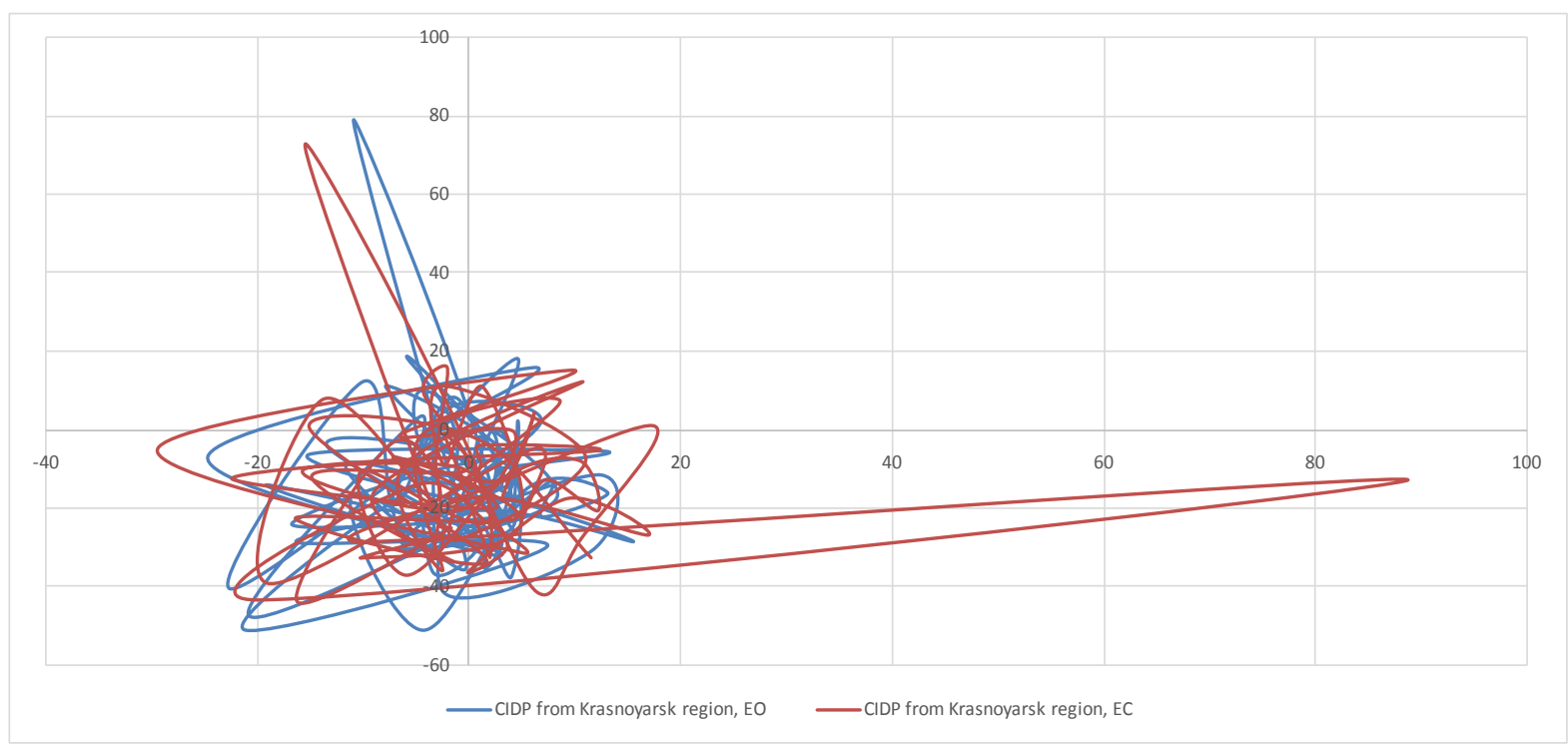

Figure 3. Statokineziogram in patients with SP-CIDP from Krasnoyarsk region: dark blue line—in phase EO; red line-in phase EC.

Republic of Sakha (Yakutia) and Krasnoyarsk region have been revealed in all investigated parameters.

The comparative analysis of results of computer stabilometry in three groups has testified to the great infringements of stability of the basic position displayed in increase of sway area in phase with EO and EC with deflection CP forward by anteropulsion type among patients with SP-CIDP from Republic of Sakha (Yakutia). Absence of deflections of Romberg quotient can specify participation of compensatory mechanisms for balance maintenance at early stages of pathological process [5] [13] [17].

\section{Conclusions}

Patients with SP-CIDP from Republic of Sakha (Yakutia) were revealed severer course of disease that was combined also with more expressed infringements of the basic position, caused by involving of proprioceptive analyzer. 


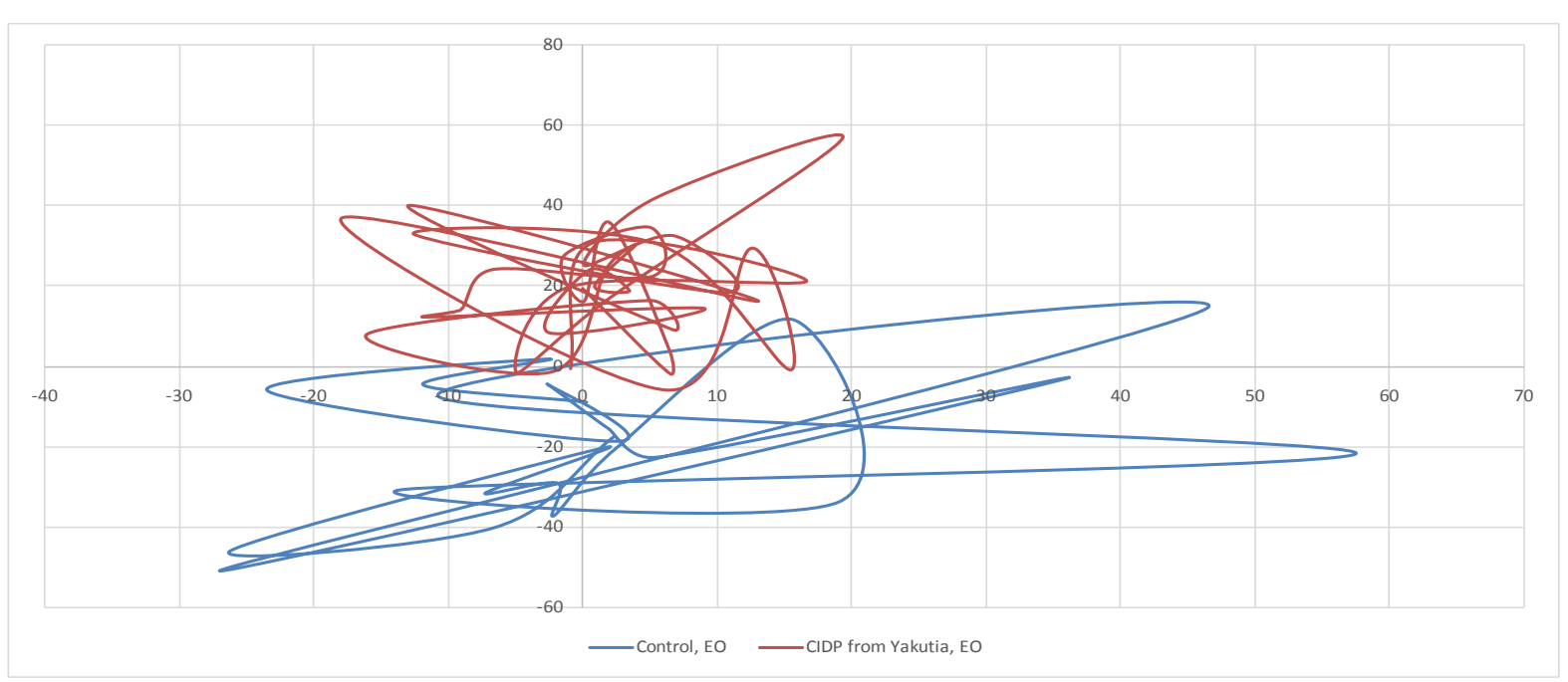

(a)

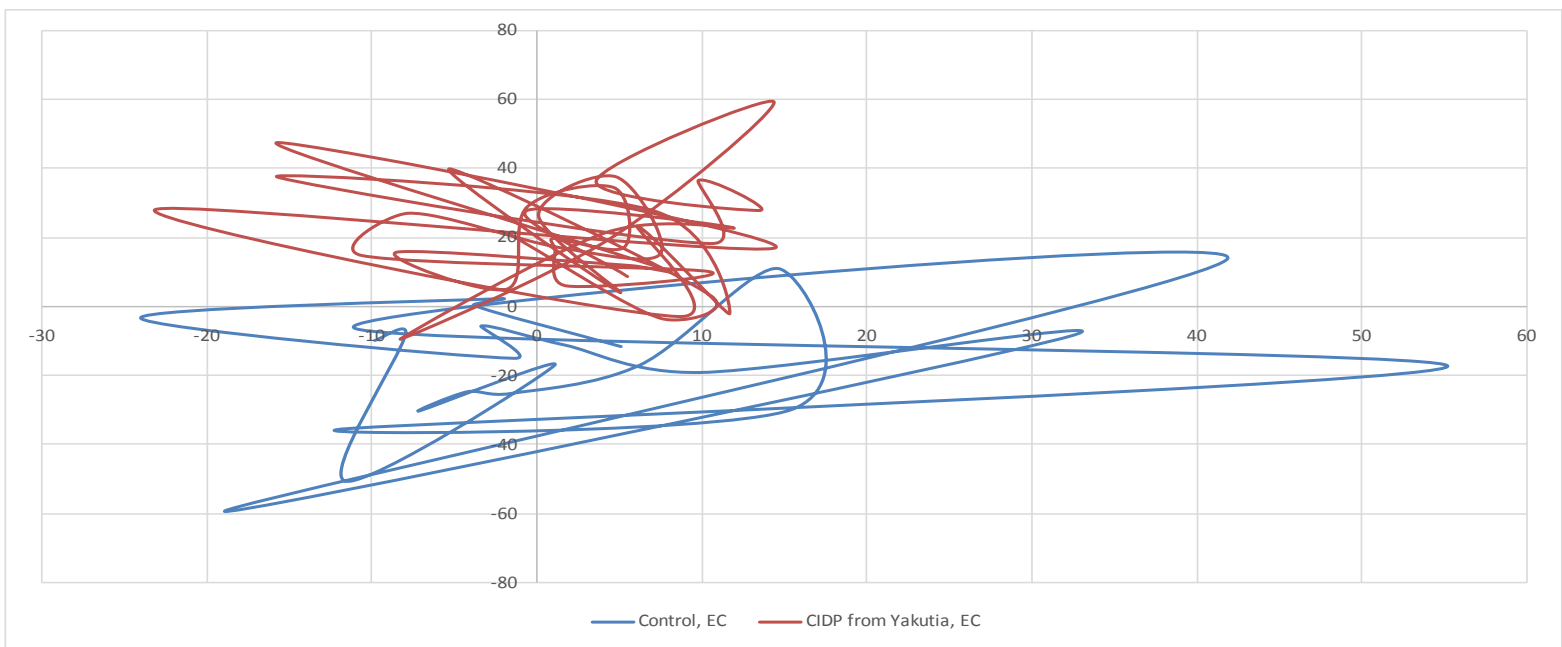

(b)

Figure 4. Statokineziogram of patients with SP-CIDP from Republic of Sakha (Yakutia) (red line) in comparison with control group (dark blue line): (a) in phase EO; (b) in phase EC.

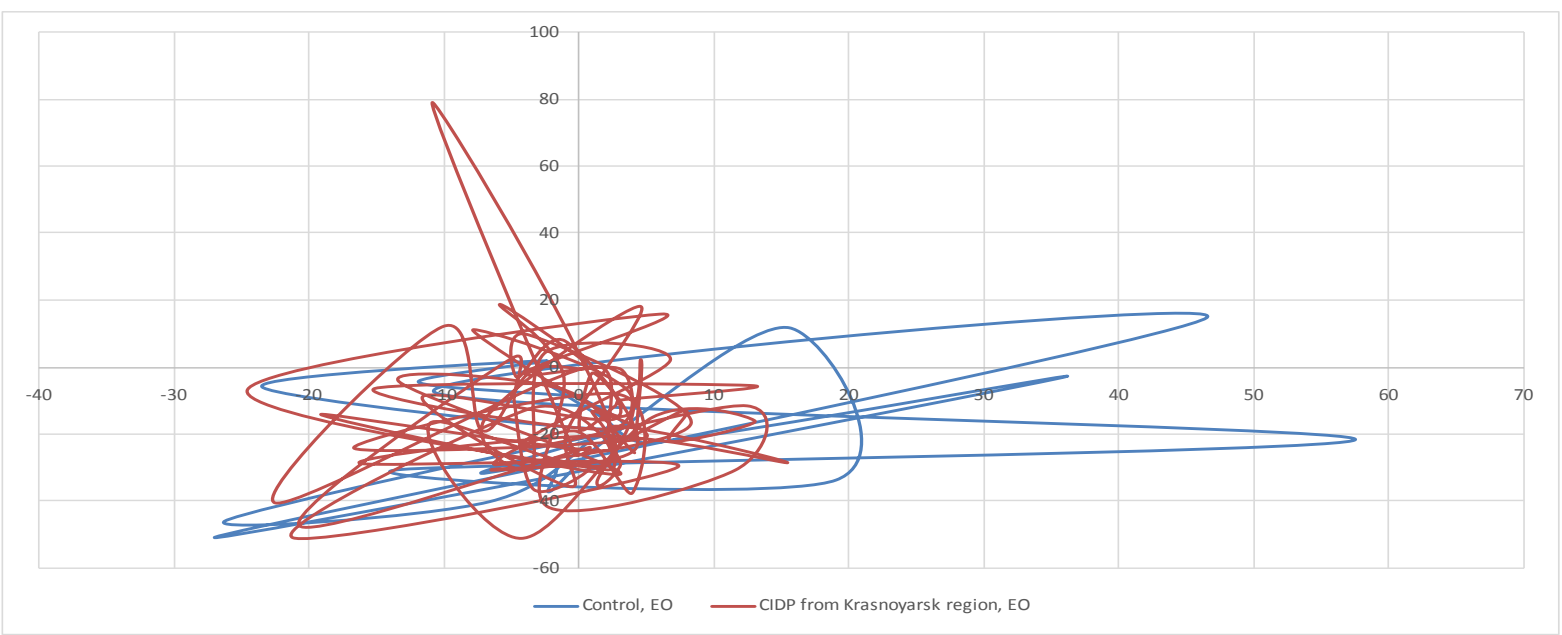

(a) 


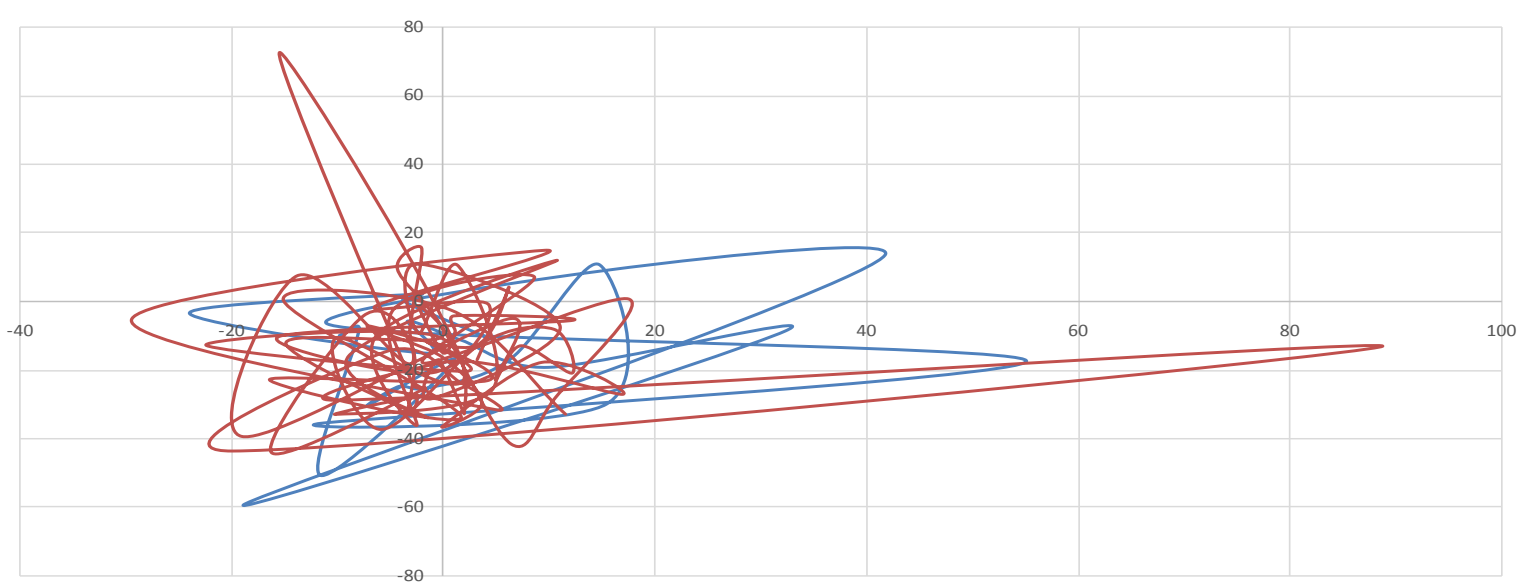

—Control, EC —CIDP from Krasnoyarsk region, EC

(b)

Figure 5. Statokineziogram of patients with SP-CIDP from Krasnoyarsk region (red line) in comparison with control group (dark blue line): (a) in phase EO; (b) in phase EC.

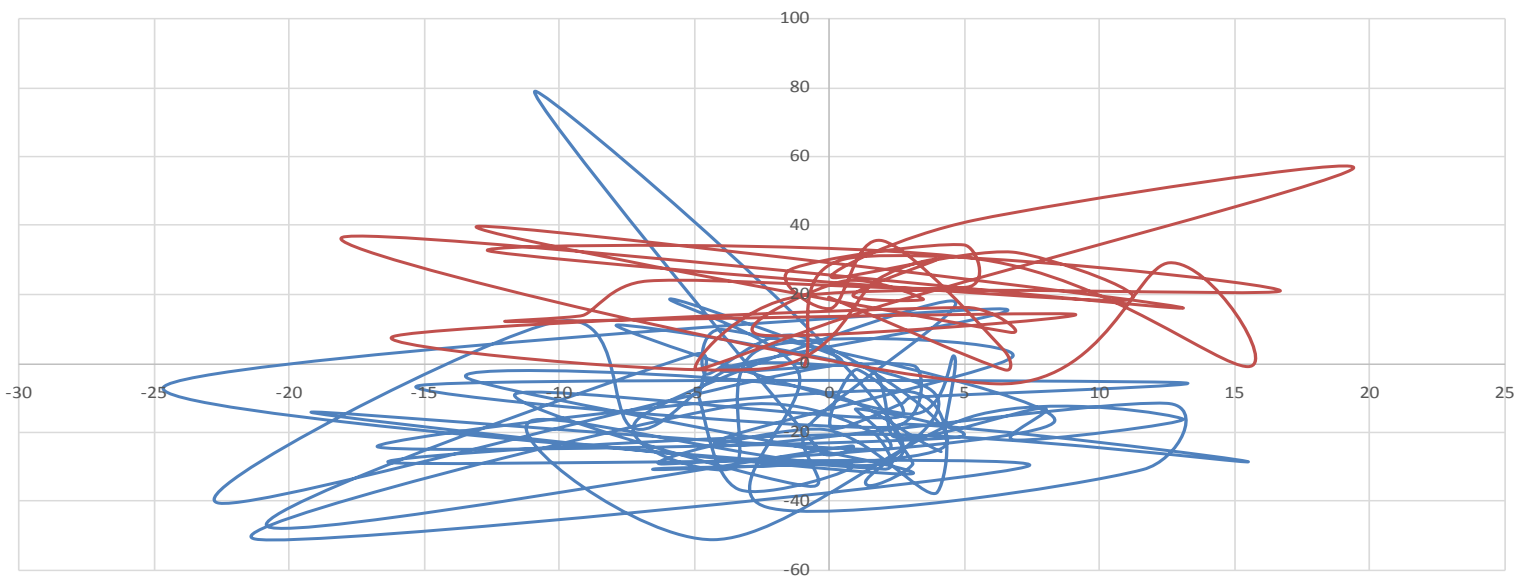

CIDP from Krasnoyarsk region, EO —CIDP from Yakutia, EO

(a)

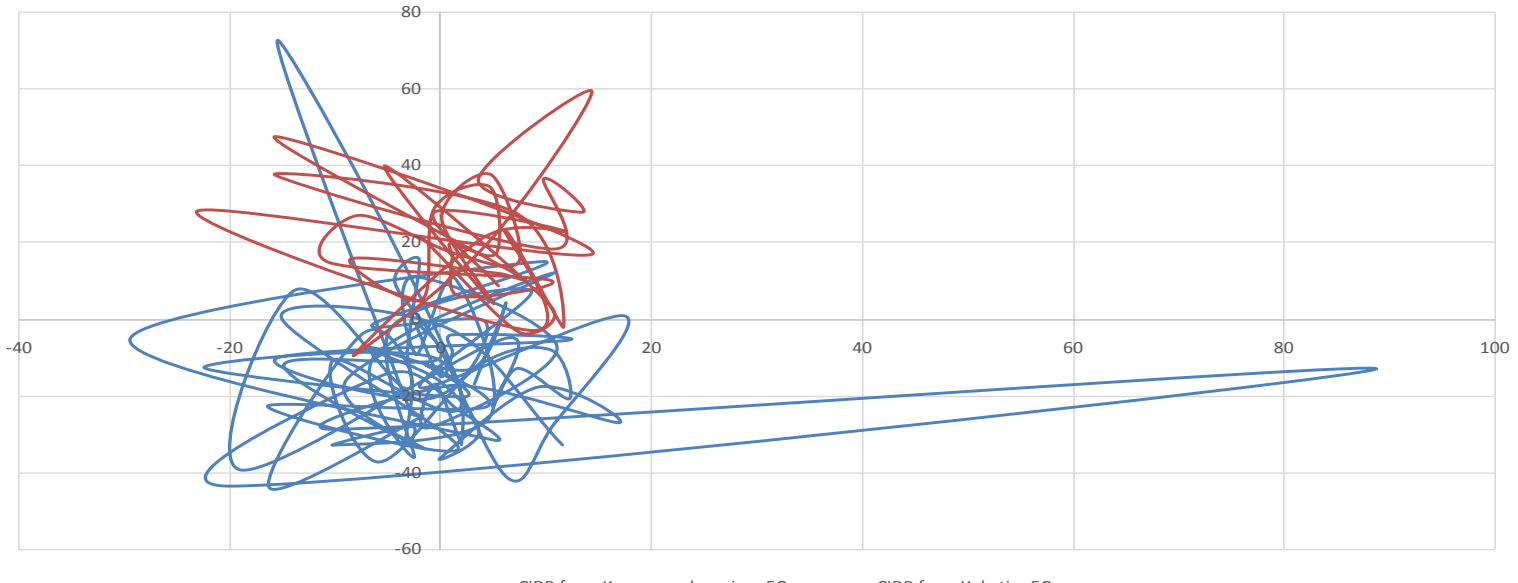

(b)

Figure 6. Statokineziogram of patients with SP-CIDP from Krasnoyarsk region (dark blue line) and Republic of Sakha (Yakutia) (red line): (a) in phase EO; (b) in phase EC. 
The method of computer stabilometry allows estimating objectively presence and degree of manifestation of postural disorders among patients with SP-CIDP [17]. Instability of the basic position among patients with SPCIDP, revealed during research, could be explained by involving of proprioceptive systems. Dynamic supervision of stabilometric indexes can be used as control of efficacy of treatment and course.

\section{Conflict of Interest}

The authors declare that they have no conflict of interests.

\section{References}

[1] (2014) Diagnosis Diabetic Neuropathy. In: Shnayder, N.A. and Petrova, M.M., Eds., Medica, Moscow.

[2] Popova, T.E., Shnayder, N.A., Petrova, M.M., Goncharova, S.I., Gazenkampf, K.A. and Nikolaeva, T.Ya. (2014) Dynamics of Vibration Sensitivity Changes According to Computer Pallestesiometry in Acquired and Genetically Determined Forms of Polyneuropathy, Class Myelinopathy. Siberian Medical Review, 4, 69-74.

[3] Popova, T.E., Shnayder, N.A., Petrova, M.M., Kantimirova, E.A., Gazenkampf, K.A., Diuzhakov, S.K. and Nikolaeva, T.Ya. (2014) Computer Pallestesiometry as a Prospective Method of Diagnostics Sensory Form of Chronic Inflammatory Demyelinating Polyneuropathy. Siberian Medical Review, 5, 79-85.

[4] Scoppaa, F., Capra, R., Gallamini, M. and Shiffer, R. (2013) Clinical Stabilometry Standardization. Basic DefinitionsAcquisition Interval-Sampling Frequency. Journal of Gait and Posture, 2, 290-292.

[5] Nardone, A., Galante, M., Pareyson, D. and Schieppati, M. (2007) Balance Control in Sensory Neuron Disease. Clinical Neurophysiology, 118, 538-550. http://dx.doi.org/10.1016/j.clinph.2006.11.012

[6] Nardone, A., Tarantola, J., Miscio, G., Pisano, F., Schenone, A. and Schieppati, M. (2000) Loss of Large-Diameter Spindle Afferent Fibres Is Not Detrimental to the Control of Body Sway during Upright Stance: Evidence from Neuropathy. Experimental Brain Research, 135, 155-162.

[7] Nardone, A. and Schieppati, M. (2004) Group II Spindle Fibres and Afferent Control of Stance. Clues from Diabetic Neuropathy. Clinical Neurophysiology, 115, 779-789. http://dx.doi.org/10.1016/j.clinph.2003.11.007

[8] Edouard, P., Gasq, D., Calmels, P. and Degache, F. (2014) Sensorimotor Control Deficiency in Recurrent Anterior Shoulder Instability Assessed with a Stabilometric Force Platform. Journal of Shoulder and Elbow Surgery, 3, 355-360. http://dx.doi.org/10.1016/j.jse.2013.06.005

[9] Schieppati, M. and Nardone, A. (1999) Group II Spindle Afferent Fibers in Humans: Their Possible Role in the Reflex Control of Stance. Progress in Brain Research, 123, 461-472. http://dx.doi.org/10.1016/S0079-6123(08)62882-4

[10] Usachev, V.I., Docenko, V.I., Cononov, A.F. and Artemov, V.G. (2009) The New Methodology of Stabilometric Diagnosis Disorders of Body Balance Function. Bulletin of Otorhinolaryngology, 3, 19-22.

[11] Popova, N.F., Shagaev, A.S., Demina, T.L. and Boyco, A.N. (2009) Research of Dynamic Stabilometry as Monitoring of Motor and Coordination Disorders during Rehabilitation in Patients with Multiple Sclerosis. Journal of Neurology and Psychiatry, 1, 35-39.

[12] Skvortsov, D.V. (2010) Stabilometric Investigations. Maska, Moscow.

[13] Popova, T.E., Tappahov, A.A., Shnaider, N.A., Petrova, M.M., Nikolaeva, T.Y., Konnikova, E.E., Kozhevnikov, A.A., Ammosov, V.G. and Vinokurova, N.E. (2015) Diagnostics Algorithm of Diabetic Polyneuropathy in Prediction of Clinical Course. Wiadomości Lekarskie, 4, 559-563.

[14] Raffi, M., Piras, A., Persiani, M. and Squatrito, S. (2014) Importance of Optic Flow for Postural Stability of Male and Female Young Adults. European Journal of Applied Physiology, 1, 71-78.

[15] Bellomo, R.G., Iodice, P., Savoia V., Saggini, A., Vermiglio, G. and Saggini, R. (2009) Balance and Posture in the Elderly: An Analysis of a Sensorimotor Rehabilitation Protocol. International Journal of Immunopathology and Pharmacology, 22, 37-44.

[16] Grjibovsky, A.M. (2008) Analysis of Three and More Independent Groups of Quantitative Data. Human Ecology, 3, 50-58.

[17] Popova, T.E., Shnaider, N.A., Petrova, M.M., Tappakhov, A.A., Nikolaeva, T.Ya., Konnikova, E.E., Kozhevnikov, A.A. and Ammosov, V.G. (2016) On the Diagnosis of Sensory Predominant Chronic Inflammatory Demyelinating Polyneuropathy. Zabaykalski Medical Bulletin, 1, 69-76. 


\section{Submit or recommend next manuscript to SCIRP and we will provide best service for you:}

Accepting pre-submission inquiries through Email, Facebook, Linkedin, Twitter, etc A wide selection of journals (inclusive of 9 subjects, more than 200 journals)

Providing a 24-hour high-quality service

User-friendly online submission system

Fair and swift peer-review system

Efficient typesetting and proofreading procedure

Display of the result of downloads and visits, as well as the number of cited articles

Maximum dissemination of your research work

Submit your manuscript at: http://papersubmission.scirp.org/ 